\title{
COMUNICAÇÃO ORGANIZACIONAL E HUMANIZAÇÃO EM REDES DIGITAIS: ANÁLISE DE CONTEÚDO DA NUBANK NO INSTAGRAM
}

\author{
ORGANIZATIONAL COMMUNICATION AND HUMANIZATION IN DIGITAL \\ NETWORKS: NUBANK CONTENT ANALYSIS ON INSTAGRAM
}

\author{
Marcelo Pereira da Silva ${ }^{1}$ \\ Nayara Santiago Resende ${ }^{2}$ \\ Tomás Vieira Cunha ${ }^{3}$
}

\begin{abstract}
Resumo: As redes sociais digitais redinamizam e ressignificam o modo como as organizações interagem com os seus públicos. Esta emergente realidade ratifica a necessidade da gestão da comunicação por meio de políticas e estratégias de humanização tanto em ambientes off-line quanto em ambientes on-line. Baseados na análise de conteúdo, analisamos postagens, interatividade e linguagem na conexão entre a startup Nubank e seus seguidores no Instagram. Inferimos que a empresa busca atender solicitações, tirar dúvidas, responder às objeções e acolher as sugestões calcada em um contato humanizado que pode gerar credibilidade, respeito, confiabilidade e afeição por parte dos usuários.
\end{abstract}

Palavras-chave: Comunicação. Redes Digitais. Humanização. Nubank. Análise de Conteúdo.

Abstract: Digital social networks renew and give new meaning to the way organizations interact with their audiences. This emerging reality confirms the need for communication management through humanization policies and strategies both in offline and online environments. Based on content analysis, we analyze posts, interactivity, and language in the connection between the startup Nubank and its followers on Instagram. We infer that the company seeks to respond to requests, resolve doubts, respond to objections, and welcome suggestions based on a "humanized" contact that can generate credibility, respect, reliability and affection on the part of users.

Key words: Communication. Digital Network. Humanization. Nubank. Content Analysis.

Data de submissão: 26.04 .2021

Data de aprovação: 25.08.2021

Identificação e disponibilidade:

(https://revista.univap.br/index.php/revistaunivap/article/view/2618, http://dx.doi.org/10.18066/revistaunivap.v27i54.2618).

\footnotetext{
1 Docente permanente do Mestrado Interdisciplinar em "Linguagens, Mídia e Arte" e do curso de Relações Públicas da Pontifícia Universidade Católica de Campinas (PUC-Campinas). E-mail: marcelosilva rp@hotmail.com.

2 Graduada em Relações Públicas pela Pontifícia Universidade Católica de Campinas (PUCCampinas), E-mail: nayarasantiagoresende@gmail.com.

3 Graduado em Relações Públicas pela Pontifícia Universidade Católica de Campinas (PUCCampinas), E-mail: tomascunha97@gmail.com.
} 


\section{INTRODUÇÃO}

A construção de relacionamentos entre empresas e públicos é um processo que exige investimento e longanimidade, haja vista que os resultados surgem em longo prazo. A reputação duradoura não depende da percepção em determinado período, mas da junção de experiências por uma extensão temporal traduzida em signos, afetos, interações, diálogos, representações etc. Os fatores sociais, tais como amigos, família, colegas, seguidores de redes digitais, influenciam mais do que as comunicações de marketing na constituição de imagem e reputação favoráveis (KOTLER; KARTAJAYA; SETIAWAN, 2017).

Nessa esteira, tratamos das imbricações da comunicação, humanização e redes sociais digitais, considerando o atendimento humanizado da startup Nubank na rede Instagram, as possibilidades e os desafios de construção de laços e vínculos entre organizações e públicos bem como a relevância do diálogo aberto nos ambientes online (RECUERO, 2014; CARVALHO, BARICHELLO, 2013; GONÇALVES, SILVA, 2014; DI FELICE, 2017; BARICHELLO et al., 2013).

Objetivamos investigar, por meio da análise de conteúdo (BARDIN, 2011; FONSECA JUNIOR, 2005), a interatividade e o relacionamento da empresa Nubank e seus clientes/usuários no Instagram no período de 22 a 31 de agosto de 2020, problematizando a relevância da comunicação humanizada para o fortalecimento dos laços entre organizações e públicos nas redes e mídias sociais da Internet.

Inferimos que a Nubank porta uma comunicação eficiente quando se trata das trocas com os usuários conectados e dos valores que perpassam os conteúdos que produz, construindo um ethos que gera identificação e afetividade, haja vista a empresa responder aos comentários e às manifestações por meio de uma linguagem amigável e terna, processo que legitima a problemática dos relacionamentos organizacionais, fomenta a confiabilidade e a humanização.

\section{COMUNICAÇÃO, REDES DIGITAIS SOCIAIS DIGITAIS E HUMANIZAÇÃO}

As redes sociais digitais apresentam um cenário epistemológico inovador para a pesquisa, já que perpassado por categorias decorrentes de mudanças no sistema midiático virtual (BARICHELLO et al., 2013). Scolari (2010) esclarece de maneira enfática o conceito de ecologia midiática, levando em conta que: 1 . Os meios de comunicação constituem um entorno que muda percepções e cognições; 2 . Os meios são as espécies que vivem em um ecossistema e estabelecem relações entre si e com os sujeitos.

O habitar on-line erige uma ecologia dos novos meios na qual organizações, sujeitos e públicos dialogam e duelam, conversam e pelejam, interagem e "viram" a face, participam e criticam, organizam protestos e acompanham ações políticas e públicas (RECUERO, 2014). De acordo com Di Felice (2017, p. 33), a ecologia da comunicação surge como uma "arquitetura comunicante capaz de dar forma às interações entre os membros humanos e não humanos, os fluxos informativos e as territorialidades".

As redes sociais digitais servem de apoio para despertar consciência, chamar atenção, suscitar interesse, proporcionar conhecimento, garantir identificação e empatia, criar desejo e/ou suscitar expectativa; conseguir a preferência, levar à decisão, efetivar a ação, garantir e manter a satisfação pós-ação, estabelecer interação, obter fidelidade e gerar disseminação de informações (MENDES; YANAZE, 2018) e relacionamentos. 
A pesquisa acerca das redes on-line deve ter em vista o capital social, cuja natureza implica em questões como normas de confiança e reciprocidade, consenso, cooperação e compartilhamento, destacando os "componentes de pertencimento a um grupo e reconhecimento mútuo" (SANTAELLA, 2010, p. 271) que servem de pilar para que as organizações ampliem os espaços de diálogo e interação com seus públicos (GONÇALVES; SILVA, 2014). Este universo constitui emergentes facetas do sujeito contemporâneo, o qual se tornou, para Lipovetsky e Charles (2004, p.28), mais informado e mais desestruturado, mais maduro e mais instável, "mais aberto e mais influenciável, mais crítico e mais superficial, mais cético e menos profundo".

As redes digitais têm dois elementos relevantes para o seu funcionamento: 1. Os atores: compostos por empresas, grupos ou pessoas são aqueles que alimentam no individual ou no coletivo o ciberespaço; 2 . As conexões: representam as interações entre os usuários. Neste universo, os laços relacionais se formam por meio das relações sociais na interação de vários atores, apresentando, de acordo com Recuero (2014), as seguintes características:

a) Laços sociais: interações de construção, nas quais os atores constroem laços, surgindo a intimidade e o aprofundamento da relação.

b) Interações de manutenção: Mantém-se sem o aumento da intimidade, mas ocorre a fidelização do relacionamento;

c) Interações de desgaste: Ocorre o rompimento em virtude de conflitos e discordância de ideias.

Os atores sociais procuram aumentar sua visibilidade, já que estar em evidência pode gerar ampliação da credibilidade, reputação e legitimidade em um oceano de possibilidades e desafios. Os ambientes tecnológico-digitais vêm assumindo a engrenagem no contato das organizações com os públicos, tornando o conceito de relacionamento mais sólido, já que a conectividade é condição sine qua non e o atendimento humanizado promotor da fidelização, conforme pontua Souza (2018).

O reconhecimento de uma marca deriva da forma como os públicos vivem e interpretam suas experiências com ela, haja vista que quando estabelecem um relacionamento com uma marca há sempre componentes funcionais e emocionais envolvidos, pois parecem buscar e valorizar organizações que tenham um propósito maior e encontrem "espelho de empatia" em seus corações, "dando um match com seus próprios valores, crenças e sonhos" (SANTAHELENA, 2018, p.39).

$\mathrm{O}$ bom humor, a honestidade e a afetividade nos relacionamentos entre organizações e públicos aumentam a reciprocidade, o respeito e a solidariedade. $O$ atendimento "humanizado" compreende pessoas e linguagem, a escuta atenta de necessidades, críticas, elogios, descontentamentos etc., integrando a construção de relacionamentos abertos e dialogais em um tempo no qual as redes sociais digitais ganharam protagonismo, como observamos na análise de conteúdo da startup Nubank no Instagram.

\section{METODOLOGIA: ANÁLISE DE CONTEÚDO DA EMPRESA NUBANK NA REDE DIGITAL INSTAGRAM}

Levamos a efeito uma análise do conteúdo por meio da coleta de material oriundo do acompanhamento das publicações e da interatividade da Nubank na rede digital Instagram. A configuração da análise de conteúdo, para Bardin (2011), liga-se a um conjunto de técnicas de análise de comunicação que utiliza procedimentos sistemáticos e discussões de conteúdo das mensagens, considerando figuras de linguagem, manifestos, imagens, conversações, trocas etc. 
O foco no estudo do conteúdo, de acordo com Fonseca Junior (2005), justificase por servir de instrumento de inteligência organizacional para avaliação e monitoramento, haja vista que a análise de conteúdo tem duas funções: a heurística, que busca enriquecer o estudo exploratório, e a de administração de prova, que reúne hipóteses sob a forma de afirmações provisórias que podem ser verificadas quando a análise serve de prova (BARDIN, 2011). Estas funções podem coexistir e se complementar. De acordo com Krippendorff (1990), a análise de conteúdo se orienta de modo empírico, exploratório e se vincula a fenômenos reais, permitindo a avaliação crítica com independência de resultados.

Utilizamos a leitura flutuante das informações coletadas, elegendo postagens e documentos para a elaboração de indicadores. O material para a análise da presença e interatividade da Nubank no Instagram foi apurado no período de 22/08/2020 a $31 / 08 / 2020$. Escolhemos este período de forma aleatória, considerando a atualidade do conteúdo selecionado para efetuar a decomposição, codificação, enumeração e descrição analítica do corpus.

\section{RESULTADOS, CATEGORIAS E ANÁLISE DE CONTEÚDO}

O ambiente on-line proporciona novas funções e ferramentas à comunicação organizacional. Assim as instituições necessitam se ressemantizar para que possam ampliar seu potencial de atuação. Coletamos e analisamos postagens que registram táticas de relacionamento da startup Nubank, tais como atualização de aplicativo, métodos para facilitar pagamentos, novidades e datas comemorativas. Encontramos as seguintes categorias: mercadológica, institucional, comemorativa e lúdica.

Tabela 1 - Postagens na rede digital Instagram no período.

\begin{tabular}{|c|c|c|c|c|c|}
\hline Data & Categoria & Legenda & $\begin{array}{l}\text { Visualiz } \\
\text { ações }\end{array}$ & $\begin{array}{l}\text { Coment } \\
\text { ários }\end{array}$ & Curtidas \\
\hline $26 / 08 / 20$ & Comemorativa & $\begin{array}{l}\text { "E pula boleto. Cata moedinha. Pula } \\
\text { porta giratória. Cata mais moedinha. } \\
\text { E no fim não tem game over, acabar } \\
\text { com a burocracia é a fase que a } \\
\text { gente mais gosta". }\end{array}$ & 64,69 & 420 & 11.073 \\
\hline $27 / 08 / 20$ & Mercadológica & $\begin{array}{l}\text { "Pix para lá, Pix para cá, e a gente } \\
\text { aqui respondendo todas as suas } \\
\text { dúvidas. Se quiser saber mais, é só } \\
\text { entrar no link da bio". }\end{array}$ & 76.80 & 2.489 & 7.300 \\
\hline $28 / 08 / 20$ & $\begin{array}{l}\text { Institucional/ } \\
\text { informativo }\end{array}$ & $\begin{array}{l}\text { "O visual da aba de cartão de crédito } \\
\text { mudou! Em outras palavras: o que } \\
\text { era bom está ainda melhor. Abra o } \\
\text { app e conte para a gente o que você } \\
\text { achou". }\end{array}$ & 105.38 & 1.050 & 15.915 \\
\hline $31 / 08 / 20$ & Lúdica & $\begin{array}{l}\text { "A vida financeira é como uma } \\
\text { montanha russa, cheia de emoções: } \\
\text { a cada boleto a conta desce e a } \\
\text { cada TED gratuito a conta sobe, } \\
\text { mas nesse carrinho roxo chamado } \\
\text { Nubank nada sairá dos trilhos". }\end{array}$ & 20,08 & 830 & 20.820 \\
\hline
\end{tabular}

Fonte: Elaborado pelos autores (2020). 
Estas foram as 4 publicações do período estudado. Os conteúdos se encaixam nas categorias mercadológica, institucional, lúdica e comemorativa, alcançando relevante quantidade de visualizações, comentários e curtidas, como apresentamos na tabela 1. As imagens postadas pela Nubank apresentam um sistema de cores diversificadas e dinâmicas, levando os seguidores/usuários a, frequentemente, interagirem com ela.

Figura 1 - Postagem na rede digital oficial no Instagram.

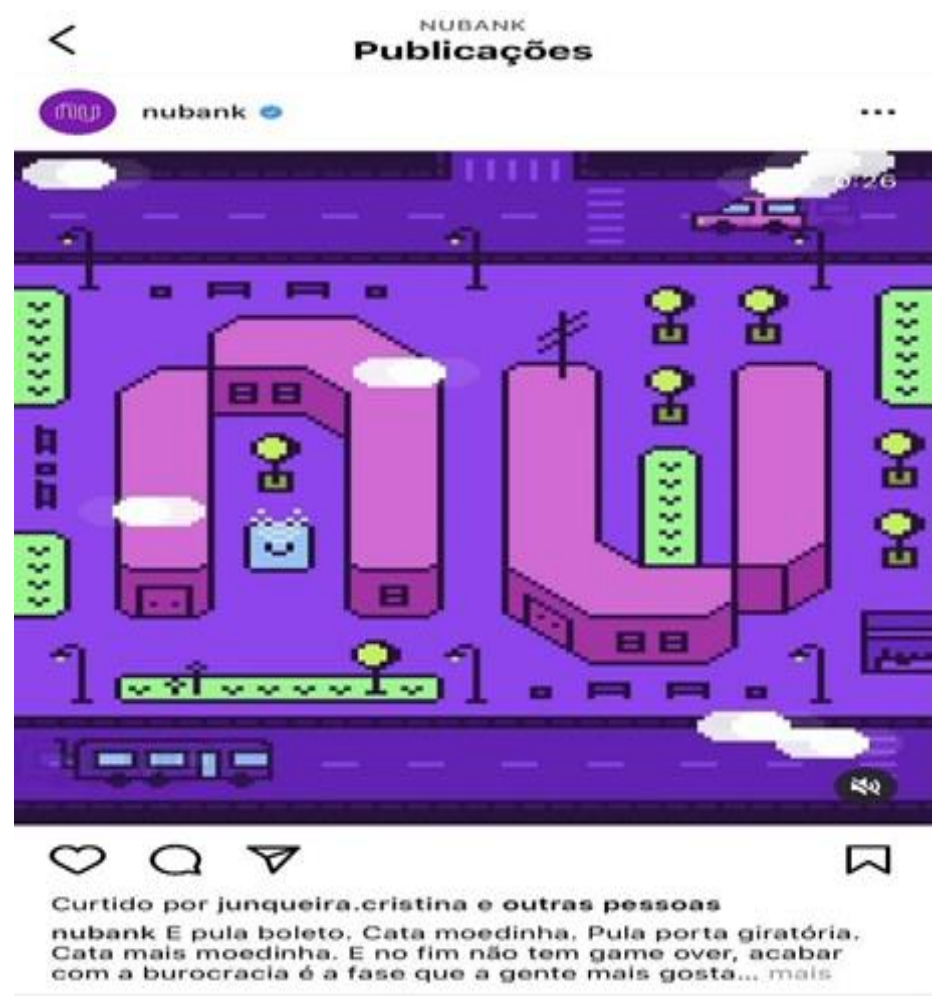

Fonte: Nubank (2020a).

Esta mensagem data de 26 de agosto de 2020 e é de natureza comemorativa, em formato audiovisual, simulando um jogo de game para festejar, no dia 29, o Dia Internacional do Gamer, agregando à comemoração as vantagens de ser cliente da Nubank. A legenda diz: "E pula boleto. Cata moedinha. Pula porta giratória. Cata mais moedinha. E no fim não tem game over, acabar com a burocracia é a fase que a gente mais gosta".

No tocante à publicação, os usuários interagiram com a marca e estabeleceram conversações: 
Tabela 2 - Postagem 1: Comentários e respostas da Nubank.

\begin{tabular}{|c|c|}
\hline Comentários de Usuários & Respostas da Nubank \\
\hline QUERO ESSE JOGO NUBANK & AGORA A GENTE TAMBÉM QUER \\
\hline $\begin{array}{l}\text { Pelo amor de Deus, criem esse jogo. Ele viciara. Em } \\
\text { vez de pontos, ser dinheiro. Muito bom. }-:\end{array}$ & $\begin{array}{l}\text { A gente não tá sabendo lidar, porque agora a } \\
\text { gente também quer esse joguinho! }\end{array}$ \\
\hline Criem esse jogo!!!! Ficou demais! & $\begin{array}{l}\text { Estamos aqui pensando, quais serias as fases? } \\
\text { Consegue pensar em alguma? }\end{array}$ \\
\hline Mas KD o link do joguinhoooo & $\begin{array}{l}\text { Vocês querem um joguinho mesmo? Contem } \\
\text { aqui pra gente }\end{array}$ \\
\hline Poderiam lançar este joguinho & $\begin{array}{l}\text { Pelo visto vocês gostaram muito hein? Será que } \\
\text { rola um joguinho mesmo? }\end{array}$ \\
\hline $\begin{array}{l}\text { Com meu roxinho comprei todos os meus jogos de } \\
\text { PS4 (-) }\end{array}$ & Qual foi o último jogo que você comprou? IIII \\
\hline $\begin{array}{l}\text { Já quero esse jogo para acumular pontos e } \\
\text { vantagens! O que acha @nubank? III! }\end{array}$ & @Kamila_bs E não é que seria uma boa ideia? \\
\hline $\begin{array}{l}\text { IIII) @nubank IIII obrigada por me mandar o cartão de } \\
\text { crédito e com um limite bacana, muito satisfeita vili (2) }\end{array}$ & @_karlabitencourt Agora é só aproveitar! \\
\hline $\begin{array}{l}\text { @nubank meu cartão virtual já foi liberado, mas meu } \\
\text { cartão físico ainda não chegou, e já tem um bom } \\
\text { tempo...Ajuda aí! }\end{array}$ & $\begin{array}{l}\text { @eu_carollaa_Chama a gente pelo chat do seu } \\
\text { app ou pelo } 08005912117 \text { para entendermos } \\
\text { melhor o seu caso, tudo bem? }\end{array}$ \\
\hline $\begin{array}{l}\text { @nubank Faz uma versão desse jogo para substituir } \\
\text { esse do dinossauro do chrome pfv. }\end{array}$ & $\begin{array}{l}\text { @arthurlobao Nossa, que ideia genial! Alô } \\
\text { produção, vem cá! }\end{array}$ \\
\hline $\begin{array}{l}\text { Eu quero esse jogo na minha mesa pra ontem } \\
\text { ahhahah }\end{array}$ & @walter_denis Como faz, a gente também quer! \\
\hline $\begin{array}{l}\text { Quero saber por que meu cartão, que recebi ontem } \\
\text { e já desbloqueei, ainda segue bloqueado } \\
\text { ?????????? Que situação constrangedora pela } \\
\text { qual passei há pouco numa farmácia! }\end{array}$ & $\begin{array}{l}\text { @thalysonmedeiros Chama a gente pelo chat do } \\
\text { seu app do seu app ou pelo } 08005912117 \text { para } \\
\text { entendermos melhor o seu caso, tudo bem? }\end{array}$ \\
\hline $\begin{array}{l}\text { Obrigado @Nubank pela linda homenagem aos } \\
\text { gamers! o } \quad \text { melhor } \quad \text { banco } \\
\text { muuuuuundo@*a\#souclienteparasempre }\end{array}$ & $\begin{array}{l}\text { @leo7lgameroficial A gente que agradece a } \\
\text { confiança, Leo. ;) }\end{array}$ \\
\hline 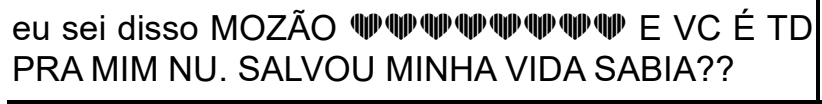 & @duka_duca Aaaa mozão :- \\
\hline $\begin{array}{l}\text { Adorável, amei me lembrou o Super Mário, Super } \\
\text { Nubank } C_{0} \| \mathbb{P} \cdot ;\end{array}$ & $\begin{array}{l}\text { @eduarda.maria.avelar Amamos o possível } \\
\text { nome! (III) }\end{array}$ \\
\hline
\end{tabular}

Fonte: Adaptado de: Nubank (2020a).

O público espera mais das organizações, por este motivo, antes de qualquer ação, elas precisam realizar pesquisas, planos de ações e planejamento para que sejam capazes de detectar interesses, necessidades e desejos. Conteúdos produzidos sem contexto e fora da linguagem dos usuários podem não ter eficiência, pois a interação é uma condição para as marcas, o público busca afinidades e anseia por conexões mais humanizadas.

Nessa postagem, a Nubank apostou na linguagem de game por estar ligada à contemporaneidade. Verificamos, com base nos comentários de alguns usuários, que a marca dialoga, se diverte e interage com os usuários de modo aberto, por meio de expressões como "Mozão" e fazendo perguntas: "Qual foi o último jogo que você 
comprou? "III', "Estamos aqui pensando, quais serias as fases? Consegue pensar em alguma?", "Vocês querem um joguinho mesmo? Contem aqui pra gente", "Pelo visto vocês gostaram muito hein? Será que rola um joguinho mesmo? "III" etc.

A postagem gerou comentários positivos para a Nubank, com seguidores pedindo para criar o jogo. Além disso, algumas interações fogem da lógica do conteúdo, com seguidores que mencionam a @nubank e escrevem que o cartão virtual não havia chegado; mas mesmo não sendo assunto relacionado à postagem, a Nubank responde indicando o que deveriam fazer. No contexto de uma sociedade cada vez mais midiatizada, é fundamental que as organizações respondam às demandas apresentadas por seguidores nas redes sociais digitais (CARVALHO et al, 2013; GONÇALVES; SILVA, 2014), já que o relacionamento do público com a marca se enreda de elementos funcionais e emocionais, e deve ter um propósito que encontre "espelho de empatia", segundo Santahelena (2018).

Já a postagem do dia 27 de agosto de 2020 está ligada à nova forma de pagamento Pix; na legenda há: "Pix para lá, Pix para cá, e a gente aqui respondendo todas as suas dúvidas. Se quiser saber mais, é só entrar no link da bio".

Figura 2 - Postagem na rede digital oficial no Instagram.
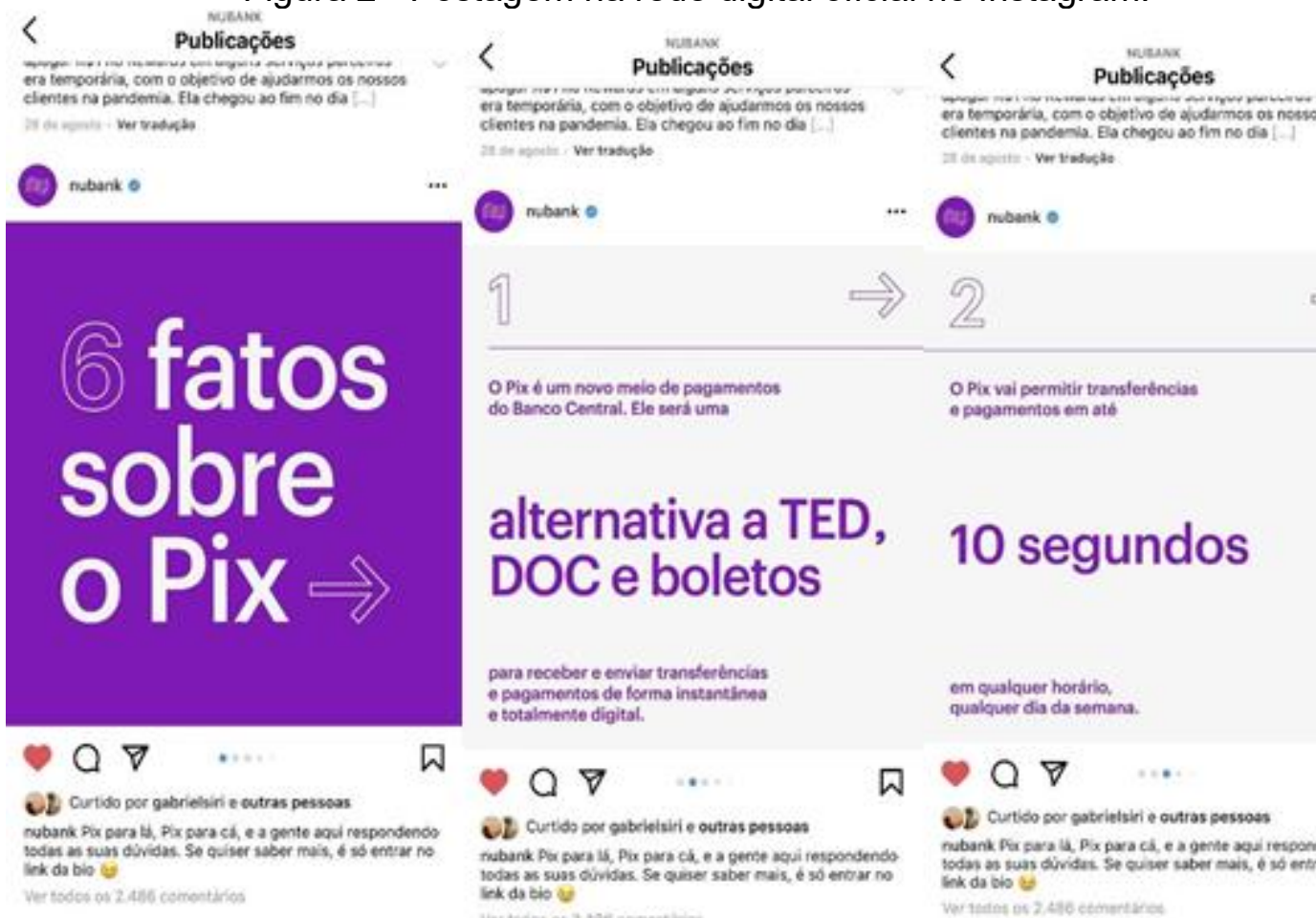
clentes na conderia. Ela chegou ao flim no dis

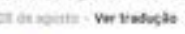

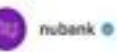
OPix 6 um novo melo de pagamentos
do Banco Central. Ele vers uma

O Pix vai permitir transfertncias pagamentos em até

alternativa a TED, DOC e boletos

\section{0 segundos}

para receber e emviar transteetincias Cogamentos de loerna instantinea

๑

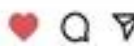

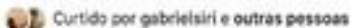

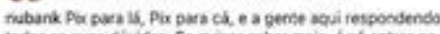

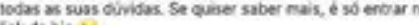

Fonte: Nubank (2020b). em qualquer horarilo. qualquer dia da semana.

ロ

$\checkmark \nabla$

๑

O2 curtido sor potrielisici eutras pessovs

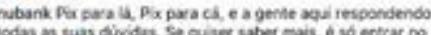
lodas an suas ofiric

A Nubank interage com os usuários e Ihes agradece na mesma linguagem amistosa, transmitindo carinho recíproco. Carvalho e Barichello (2013) destacam a importância de as organizações estimularem a inteligência coletiva e a participação nas conversas para sanarem dúvidas, indagações e trocar afeições. A publicação convida os seguidores a conversarem, contendo imagens e a disponibilidade de se entrar no link na "bio" para saber mais sobre o PIX. 
Tabela 3 - Postagem 2: Comentários e respostas da Nubank.

\begin{tabular}{|c|c|}
\hline Comentários de Usuários & Respostas da NUBANK \\
\hline Vcs são excelentes & @ketlinkcardoso Valeu pelo carinho! :-) \\
\hline $\begin{array}{l}\text { @nubank sempre inovando } \\
\text { concentro todas as minhas finanças na Nuconta.. } \\
(-)-2\end{array}$ & $\begin{array}{l}\text { @danilopoli Juntos vamos construir a revolução } \\
\text { roxa! IIII) }\end{array}$ \\
\hline Nubank, você é perfeito IIII & @tayzafogali Vocês também! III! \\
\hline E o Apple pay/Google pay? & $\begin{array}{l}\text { @oxeentebruno Estamos sempre em busca de } \\
\text { novas ideias e soluções para melhorar a } \\
\text { experiência dos nossos clientes, assim que } \\
\text { tivermos novidades avisaremos todo mundo! }\end{array}$ \\
\hline $\begin{array}{l}\text { Com esse pix vai poder transferir da nuconta para } \\
\text { poupança? }\end{array}$ & $\begin{array}{l}\text { Com esse pix vai poder transferir da nuconta para } \\
\text { poupança? }\end{array}$ \\
\hline $\begin{array}{l}\text { Estou ansiosa para a instalação do PIX no Brasil!! } \\
\text { Que bom que já está chegando no Nubank!! IIII }\end{array}$ & @quel_gontijo Ahh, também estamos! Mwi:j \\
\hline $\begin{array}{l}\text { Soooooo vemmmm PIX já "estounpronto" pra te } \\
\text { usar vievieview }\end{array}$ & @jeffbarbosaferreira vilie \\
\hline Aaae, nubank é tudo & $@$ caioalverga $\odot: \vdots$ \\
\hline $\begin{array}{l}\text { Adoro o nubank é o melhor banco digital que } \\
\text { existe. }\end{array}$ & $\begin{array}{l}\text { @marcelodelarmelina Conte sempre com a gente, } \\
\text { Marcelo! }-;\end{array}$ \\
\hline Nubank é sinônimo de liberdade!!! & @kesiarodrig @-1\|! \\
\hline $\begin{array}{l}\text { Uso o @nubank a mais de um ano, é me } \\
\text { surpreendeu principalmente o atendimento que é } \\
\text { ótimo viluiu }\end{array}$ & @tyagobarbeiro IIIIIII) \\
\hline $\begin{array}{l}\text { Melhor banco que tem, o pix vai chegar para } \\
\text { acabar com as burocracias, sou nu }(-)\end{array}$ & @_luisxgui Estamos ansiosos $(-)$ (III \\
\hline Nubank eu amo vocês & @saporski A gente te ama mais IIIIIII \\
\hline 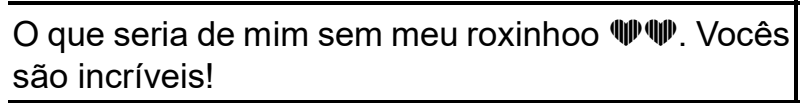 & @sra_reboucas @-) \\
\hline 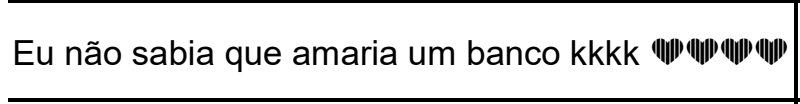 & $\begin{array}{l}\text { @ruthlerman Ficamos muito felizes em saber } \\
\text { disso! O amor é recíproco, a propósito! @) (III) }\end{array}$ \\
\hline 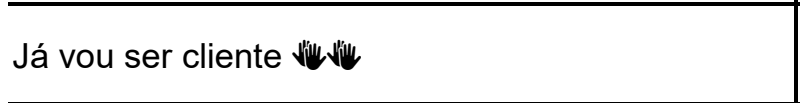 & $\begin{array}{l}\text { @denirferreira Estamos ansiosos por isso! Vc vai } \\
\text { amar. (-) }\end{array}$ \\
\hline 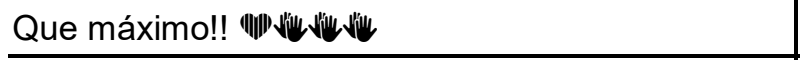 & Muito legal né?! "In: \\
\hline Tem previsão de quando? @nubank & $\begin{array}{l}\text { @caio_c_correa Em Outubro começaremos a } \\
\text { realizar o cadastro dos interessados, e a partir de } \\
\text { novembro o serviço será ativado! @-) } \| \text { in: }\end{array}$ \\
\hline O melhor baaaanco IIII) & $@$ caroline.mcastro @:) \\
\hline $\begin{array}{l}\text { Melhor cartão é o Nubank vieviu Nenhum outro me } \\
\text { dava a importância o Nubank foi muito bom para } \\
\text { uma cliente sem muitas condições }\end{array}$ & $\begin{array}{l}\text { @nalvafrutuoso Ficamos muito felizes por saber } \\
\text { disso! }\end{array}$ \\
\hline $\begin{array}{l}1 \text { Ano de relacionamento com os melhores } \|^{\|} \text {amo } \\
\text { meu roxinho }(-)\end{array}$ & @bruuna.sa Que seja o primeiro de muitos! \\
\hline
\end{tabular}

Fonte: Adaptado de: Nubank (2020b).

O conteúdo apresenta falas e reações que revelam o amor que o usuário 
demonstra ter pela Nubank, a qual retribui: "1 Ano de relacionamento com os melhores IIII' amo meu roxinho", "O melhor baaaanco", "Eu não sabia que amaria um banco kkkk

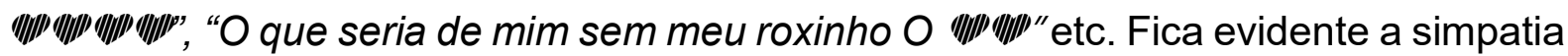
que os usuários e a empresa demonstram ter entre si.

A postagem do dia 28 de agosto se caracteriza como informativa. Sua legenda afirma que: "O visual da aba de cartão de crédito mudou! Em outras palavras: o que era bom está ainda melhor. Abra o app e conte para a gente o que você achou". A mudança ocorreu no aplicativo referente ao cartão de crédito e, na postagem, a marca solicita que os seguidores deixem opiniões sobre as transformações feitas.

Figura 3 - Postagem rede social Oficial Instagram.

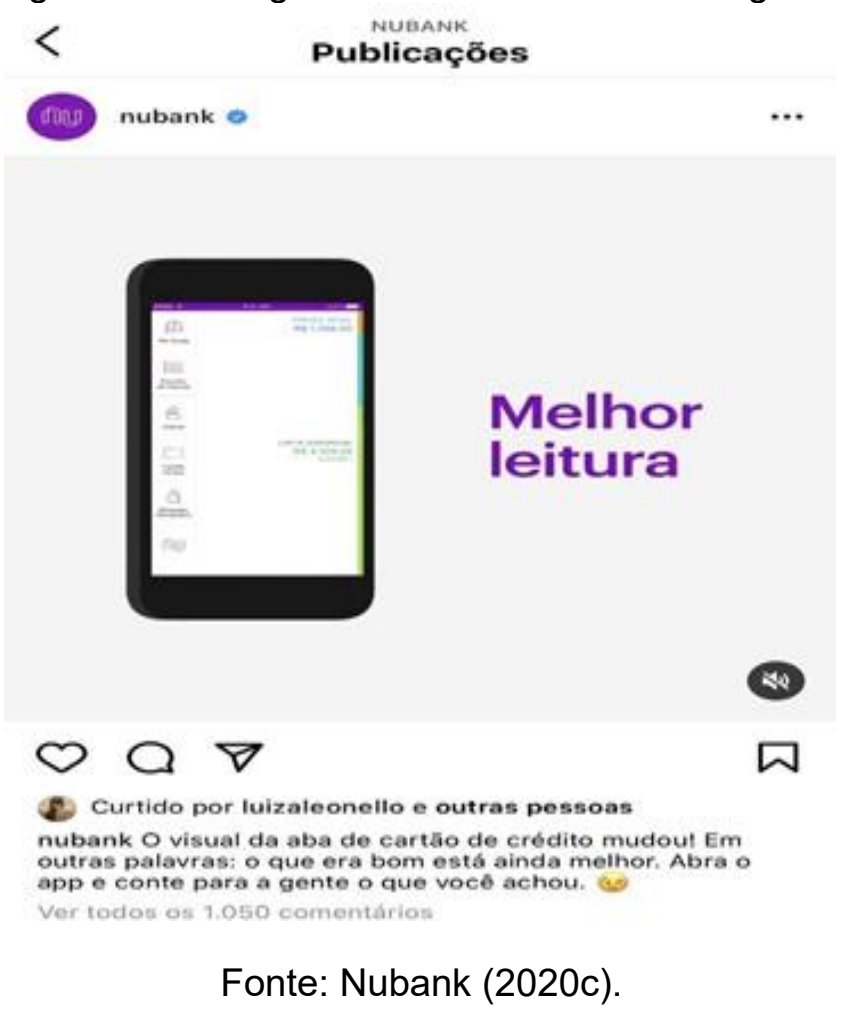

Recuero (2014) esclarece que através da interatividade entre atores, por meio de comentários, compartilhamentos, pensamentos, memes, curtidas etc. pode estreitar as relações, fortalecer os laços e vínculos sociais, gerando uma disposição positiva e interações de manutenção que, para Mendes e Yanaze (2018), produzem identificação, empatia, fidelidade e lealdade. 
Tabela 4 - Postagem 3: Comentários e respostas da Nubank.

\begin{tabular}{|c|c|}
\hline Comentários de Usuários & Respostas da NUBANK \\
\hline $\begin{array}{l}\text { O meu mudou faz tempo, só o que não } \\
\text { mesmo é o meu amor por vocês. IIII }\end{array}$ & $\begin{array}{l}\text { @davidanaolevonada Own, que fofura! Saiba que } \\
\text { esse amor é recíproco, viu?! (II) }\end{array}$ \\
\hline Ficou perfeito! Amo muito um roxinho IIII) & $\begin{array}{l}\text { @vinidaniel01 Muito obrigado pelo feedback! Isso } \\
\text { mostra que estamos no caminho certo, podendo } \\
\text { melhorar cada vez mais! Sempre que precisar, } \\
\text { conte com a gente. } \odot \text { (III) }\end{array}$ \\
\hline $\begin{array}{ll}\text { stou } & \text { amando } \\
\text { (II) }\end{array}$ & $\begin{array}{l}\text { @joserenersouza Ficamos felizes em ler isso! } \\
\text { (wi) Se precisar de algo, estaremos sempre a } \\
\text { disposição em nossos canais de atendimento! }- \text { a }\end{array}$ \\
\hline Só quero meu dinheiro de volta que pegaram & $\begin{array}{l}\text { @justo.gean Para entendermos melhor a sua } \\
\text { situação e direcionarmos ao time responsável, } \\
\text { poderia nos chamar na DM e nos dar mais } \\
\text { detalhes sobre o seu caso? }\end{array}$ \\
\hline @nubank ativa minha conta de volta & $@$ nubank ativa minha conta de volta \\
\hline $\begin{array}{l}\text { O Nubank "bloqueou" } 600 \text { reais da minha filha e } \\
\text { agora tá pedindo mil e um documento para } \\
\text { devolver o dinheiro que por boleto ela tirou da } \\
\text { minha conta!! Conselho não movimente dinheiro } \\
\text { nele !! @nubank }\end{array}$ & $\begin{array}{l}\text { @yatita.48 Para entendermos melhor a situação e } \\
\text { orientar de maneira devida, precisamos que a } \\
\text { titular de conta entre em contato com a gente } \\
\text { através dos nossos canais de atendimento: } \\
\text { https://sou.nu/contato }\end{array}$ \\
\hline Eu a@o o meu ROXINHO IIIIIIII) (III) & $@$ @mari.jooh É recíproco. <3 \\
\hline Eu amooo $\|(\|\|,,\|$,$\| zero defeitos$ & @r_llacerda Nós também amamos vocês! IIII \\
\hline $\begin{array}{l}\text { Meu irmão gerou um boleto de } 700,00 \text { para } \\
\text { depósito porém digitou o código de barras } \\
\text { invalido o crédito caiu para terceiros em alguma } \\
\text { conta nubank meu irmão entrou em contato com } \\
\text { a central sem retorno e isso já faz um mês, ou } \\
\text { seja, perdeu dinheiro, no início é sempre essa } \\
\text { maravilha todo mundo elogiando mais passem } \\
\text { por algum problema e quero ver esses elogios. } \\
\text { Fica a dica }\end{array}$ & $\begin{array}{l}\text { @tonmarques39 Olá, como você relata, houve um } \\
\text { erro de digitação por parte dele e isso causou esse } \\
\text { erro, porém peça para o seu irmão entrar em } \\
\text { contato conosco através do telefone, assim } \\
\text { conseguiremos entender melhor o caso. } \\
\text { Precisamos de alguns comprovantes por e-mail e } \\
\text { faremos algumas verificações para entender o } \\
\text { ocorrido. O contato ele encontra aqui: } \\
\text { https://nubank.com.br/contato }\end{array}$ \\
\hline
\end{tabular}

Fonte: I Adaptado de: Nubank (2020c).

Nessa postagem, verificamos que nem todos os comentários são referentes ao assunto da publicação. Há, também, comentários com dúvidas e alguns negativos, tais como: "Preciso de ajuda, não consigo, não lembro a senha do app, não consigo entrar", "Só quero meu dinheiro de volta que pegaram", "O Nubank bloqueou 600 reais da minha filha e agora tá pedindo mil e um documento para devolver o dinheiro que por boleto ela tirou da minha conta!! Conselho: não movimente dinheiro nele!! @nubank”, “Meu irmão gerou um boleto de 700,00 para depósito, porém digitou o código de barras invalido o crédito caiu para terceiros em alguma conta Nubank, meu irmão entrou em contato com a central sem retorno e isso já faz um mês, ou seja, perdeu dinheiro, no início é sempre essa maravilha, todo mundo elogiando mas passem por algum problema e quero ver esses elogios. Fica a dica ?”".

Chama a atenção que mesmo diante de assuntos sem relação com a postagem, a Nubank respondeu de forma humanizada, demonstrando uma atitude aberta e honesta frente às críticas e aos elogios que recebeu no tocante à atualização do aplicativo, inclusive direcionando os usuários para outros canais de relacionamento.

Posteriormente, a publicação do dia 31 de agosto abordou a realidade de 
pessoas que enfrentam dificuldades para pagar suas dívidas e que, por meio das facilidades disponibilizadas pela Nubank, podem ter um controle maior sobre as contas. A legenda da postagem, cuja imagem é uma montanha russa com a cor roxa que faz alusão à marca, diz: "A vida financeira é como uma montanha russa, cheia de emoções: a cada boleto a conta desce e a cada TED gratuito a conta sobe, mas nesse carrinho roxo chamado Nubank nada sairá dos trilhos".

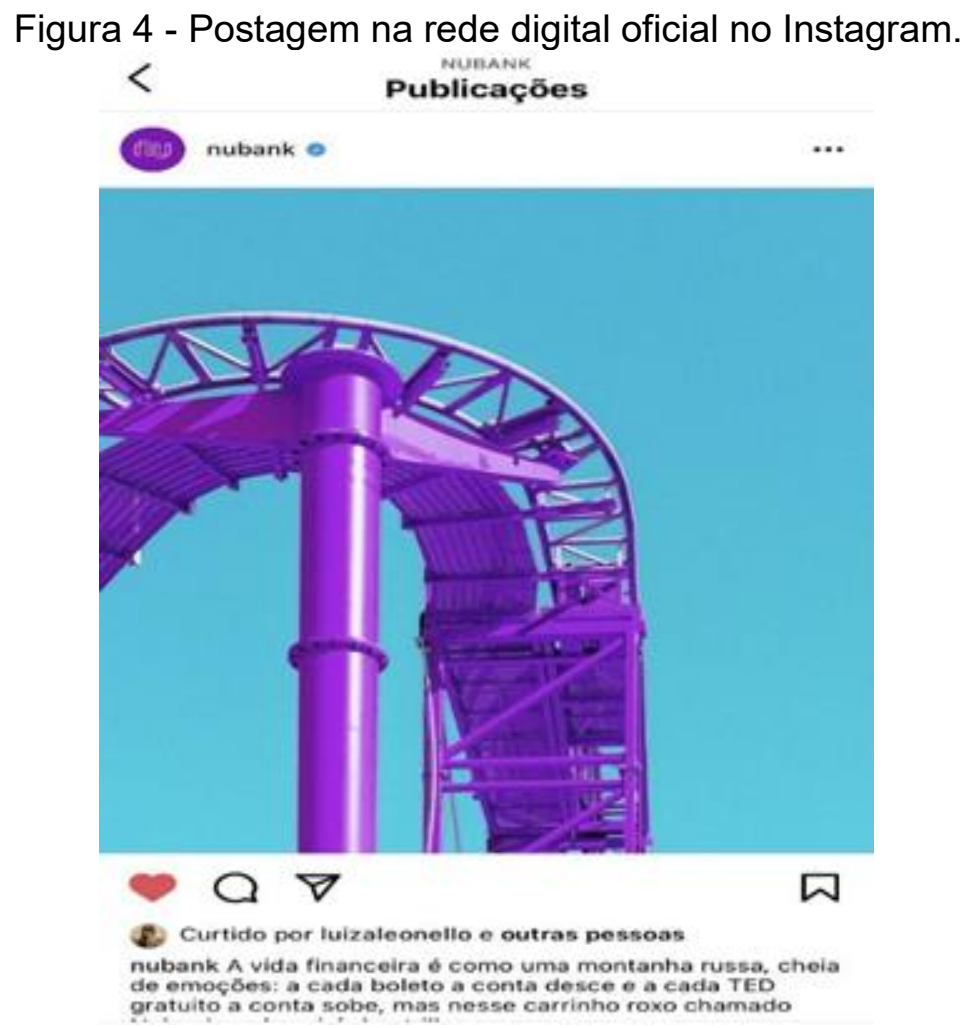

Fonte: Nubank (2020d).

Kotler, Kartajaya e Setiawan (2017) assinalam que as organizações devem buscar novos clientes, atrair a sua atenção e fidelizá-los por meio de ações que ofereçam benefícios, facilidades, pontualidade, confiabilidade etc. A experiência do sujeito com as marcas gera imagens que devem ser valorizadas e geridas como fator constituinte de uma realidade que pode aperfeiçoar a vida das organizações. As redes virtuais tornam as relações mais estreitas, mas as trocas ficam mais complexas, haja vista que na intercompreensão, o outro pode até "estar ali", mas nem sempre está aberto ao diálogo honesto e respeitoso. 
Tabela 5 - Postagem 4: Comentários e respostas da Nubank.

\begin{tabular}{|c|c|}
\hline Comentários de Usuários & Respostas da NUBANK \\
\hline $\begin{array}{l}\text { @nubank ta na hora do Nupark o parque de } \\
\text { diversão do @nubank }\end{array}$ & @jemsaraujo Já pensou? kkkk \\
\hline $\begin{array}{l}\text { Nubank o melhor banco do mundo } \\
\text { Numv }\end{array}$ & @rosivaldo1985 Com os melhores clientes. <3 \\
\hline Esperando a @nubank no Samsung Pay $(2)$ & $\begin{array}{l}\text { @brianmarinho__Por enquanto não temos } \\
\text { previsão, tá? Mas se algo mudar avisaremos todo } \\
\text { mundo.;) }\end{array}$ \\
\hline $\begin{array}{l}\text { Eu pago em dia minha fatura, já tenho quase } 1 \\
\text { ano, e vcs não aumentam meu crédito }\end{array}$ & $\begin{array}{l}\text { @amarobertto São vários critérios que } \\
\text { influenciam no aumento, tá? Mas por aqui não } \\
\text { conseguimos interferir. Faz o pedido pelo app e se } \\
\text { precisar de detalhes, chama a gente no } \\
\text { atendimento. ;) }\end{array}$ \\
\hline $\begin{array}{l}\text { Esse cartão é MARAVILHOSO!! AMOOOO } \\
\text { demais meu roxinho (III) }\end{array}$ & @nevesvirginia15 A gente te ama mais ainda! (III) \\
\hline Uma montanha russa sem surpresas 사피 & $\begin{array}{l}\text { @rogerioisidori1 Haha! É isso. Tudo sob controle. } \\
; \text {; }\end{array}$ \\
\hline $\begin{array}{l}\text { A pessoa não se aguenta, onde ela chega faz } \\
\text { propaganda desse cartão maravilhoso (III) }\end{array}$ & $\begin{array}{l}\text { @gleyson_ Que maravilha! A gente fica feliz em } \\
\text { saber, viu? Conta com a gente! }\end{array}$ \\
\hline Meu amor da minha vida meu roxinho $(-) \cdot(-)$ & $@$ @fernanda.sf.oficial A gente te ama tbm! $<3$ \\
\hline $\begin{array}{l}\text { O atendimento pelo chat é sempre ótimo. } \\
\text { Atendentes super educados e rápidos para } \\
\text { solucionar o problema. Nada a reclamar, só } \\
\text { agradecer! IIII }\end{array}$ & $\begin{array}{l}\text { @ camilalicurgogm Ficamos muito felizes com } \\
\text { seu comentário, isso mostra que estamos no } \\
\text { caminho certo. } \\
\text { Sempre que precisar, continue contando com a } \\
\text { gente! (III) }\end{array}$ \\
\hline $\begin{array}{l}\text { Eu amo um banco e quero converter todo mundo } \\
\text { q conheço pro \#timedoroxinho }\end{array}$ & @mserikaespindola Obrigado pelo carinho! IIII \\
\hline Amo esse banco & @skywalkedA gente também te ama! III! \\
\hline O melhor que já pude ter. Falo com propriedade. & @kaio._bs fofo IIII \\
\hline $\begin{array}{l}\text { Esperando o Nubank no Apple Pay pra sair } \\
\text { definitivamente dos outros bancos }\end{array}$ & $\begin{array}{l}\text { @ denysondantas Assim que tivermos novidades, } \\
\text { avisaremos! IIII) }\end{array}$ \\
\hline $\begin{array}{l}\text { Mas com o @nubank em nem me preocupo em } \\
\text { minha vida financeira ser uma montanha russa, } \\
\text { pois sei que posso confiar }\end{array}$ & \begin{tabular}{|l|l|} 
@florian1 Obrigado pela confiança! IIII \\
\end{tabular} \\
\hline Tá faltando só aumentar meu limite & $\begin{array}{l}\text { @raf.phoenix Você pode solicitar uma análise de } \\
\text { aumento de limite diretamente pelo seu app. }\end{array}$ \\
\hline Bom demais IIII & $@$ brsilvar IIIII \\
\hline Queria ganhar um mimo do Nubank & $\begin{array}{l}\text { @fadacristal Os mimos são ações pontuais que } \\
\text { realizamos para surpreender de forma positiva. } \\
\text { Quem sabe você não é a próxima? IIII }\end{array}$ \\
\hline
\end{tabular}

Fonte: Adaptado de: Nubank (2020d).

Os comentários dos usuários e as respostas da empresa mostram trocas carinhosas representadas por signos como o coração roxo (III) e expressões: "Amo esse banco", "O atendimento é ótimo", "Esse cartão é maravilhoso", "A pessoa não se aguenta, onde ela chega faz propaganda desse cartão maravilhoso", indicando a afetividade, simpatia e consideração que permeiam e norteiam o relacionamento da 
marca com os públicos digitais.

Os públicos estão imersos em uma cultura da conexão na qual são influenciados e estimulados por ações comerciais que buscam atender às suas necessidades e desejos em um habitar (DI FELICE, 2017) altamente interativo e desafiador para as organizações. Estas devem desenvolver habilidades para construir um ethos responsável, sério, credível, virtuoso, competente e humanizado, todavia alicerçado mais no "ser" do que no "parecer ser" tão característico da atualidade.

$\mathrm{Na}$ análise em tela, a startup Nubank apresenta, com base em conteúdos e na interatividade construída por meio do Instagram, uma comunicação humanizada e um atendimento perpassado por uma linguagem amistosa que respeita a singularidade dos indivíduos, os quais constituem fábricas de significações e afeições que devem ser tomadas em conta pelas organizações contemporâneas.

\section{CONCLUSÕES}

As redes on-line constituem relevante capital social e se caracterizam pela possibilidade de confiança, reciprocidade, cooperação, compartilhamento etc., servindo como pilar para que as organizações potencializem espaços de diálogo, conversação e interação (GONÇALVES; SILVA, 2014) em um universo no qual, paradoxalmente, os sujeitos tornaram-se, conforme Lipovetsky e Charles (2004), mais informados, desestruturados, instáveis, abertos, influenciáveis, críticos, superficiais e céticos.

Ao analisarmos o conteúdo, a interatividade e o relacionamento da Nubank com os clientes/usuários no Instagram, a questão do cuidado e do atendimento humanizado evidencia o potencial do ambiente virtual, pois é necessário tratar os públicos de modo "especial", por meio de uma linguagem que o coloque como pessoa dotada de emoções, sentimentos e sonhos, para que se fomente, reciprocamente, a empatia e a estima (SANTAHELENA, 2018).

Conforme observamos, as estratégias de relacionamento da Nubank levam os públicos a amarem e promoverem a marca, já que a seguem e interagem com ela de forma aberta e humanizada, o que representa um diferencial competitivo que fortalece a imagem e a reputação de qualquer organização em um contexto de frenética midiatização e competição acirrada entre diversos players.

A análise de conteúdo da Nubank comprova que a relação com os clientes por meio de mídias e redes digitais liga-se, umbilicalmente, a um mundo cada vez mais globalizado: é fulcral que as empresas estejam sempre conectadas com os seus seguidores. A relação entre a Nubank e seu público gera transparência e afeição: "Amo esse banco", "O atendimento é ótimo", "Esse cartão é maravilhoso", "A pessoa não se aguenta, onde ela chega faz propaganda desse cartão maravilhoso", "1 Ano de relacionamento com os melhores, "IIII amo meu roxinho", "O melhor baaaanco", "Eu não sabia que amaria um banco kkkk IIIIIIIIIIIIIIIII)", "O que seria de mim sem meu roxinho

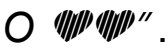

Esta conjuntura aponta a necessidade de as organizações constituírem relacionamentos baseados em uma linguagem informal, calcada em produções audiovisuais divertidas, informações de utilidade pública, interações abertas e humanizadas com os usuários. O relacionamento da Nubank se mostra pessoalizado, haja vista entrever certo cuidado em responder e interagir com os comentários, criar publicações e conversar com os seguidores. Por se tratar de uma marca digital, a empresa parece motivada a responder de forma individualizada e carinhosa, seja 
sugestão, seja elogio, seja crítica.

Concluímos que a interatividade e o relacionamento das organizações nas redes on-line devem evitar o medo do outro e o receio da exposição de fragilidades e equívocos operacionais, relacionais, humanos e técnicos. As sociedades constituem fábricas de significações e as organizações, igualmente, são um viveiro de sentidos e trocas que podem se ancorar sob o medo ou a confiança, o que é sempre uma escolha que comporta uma decisão. As organizações intrépidas estão pavimentando as vias da humanização e da reciprocidade nas redes sociais digitais. Esta é uma pista que produz estratégias para se enfrentarem os desafios e se abraçarem as possibilidades do presente e do porvir.

\section{REFERÊNCIAS}

BARDIN, Laurence. Análise de conteúdo. Portugal: Edições 70, 2011.

BARICHELLO, Eugenia Mariano da Rocha et al. Estendendo as práticas de Relações Públicas sob a perspectiva teórica da ecologia das mídias. In: RUBLESCKI, Anelise; BARICHELLO, Eugenia Mariano da Rocha (Orgs.). Ecologia da Mídia. Santa Maria: FACOS, 2013, p.129-154.

CARVALHO, Luciana Menezes; BARICHELLO, Eugenia Mariano da Rocha. Legitimação das organizações no ecossistema digital. In: RUBLESCKI, Anelise; BARICHELLO, Eugenia Mariano da Rocha (Orgs.). Ecologia da Mídia. Santa Maria: FACOS, 2013. p. 61-77.

DI FELICE, Massimo. Net-ativismo: da ação social para o ato conectivo. São Paulo: Paulus, 2017.

FONSECA JÚNIOR, Wilson Corrêa da. Análise de conteúdo. In: DUARTE, Jorge; BARROS, Antônio (Orgs.). Métodos e Técnicas de pesquisa em comunicação. São Paulo: Atlas, 2005, p. 280-304.

GONÇALVES, Elizabeth Moraes; SILVA, Marcelo da. A amplitude do diálogo nas redes sociais digitais: sentidos em construção. In: GOULART, Elias E. (Org.). Mídias sociais: uma contribuição de análise. Porto Alegre: EDIPURCS, 2014, p. 85-105.

KRIPPENDORFF, Klaus. Metodología de análisis de contenido. Barcelona: Paidós, 1990.

KOTLER, Philip; KARTAJAYA, Hermawan; SETIAWAN, Iwan. Marketing 4.0: Do Tradicional ao Digital. Rio de Janeiro: Sextante, 2017.

LIPOVETSKY, Gilles; CHARLES, Sébastien. Os tempos hipermodernos. São Paulo: Barcarolla, 2004.

MENDES, Flávia Cristina Martins; YANAZE, Mitsuru Higuchi. Marketing e Relações Públicas: Promovendo Diálogo públicos nas redes sociais. Organicom, São Paulo, v. 15, n. 29, p. 21-29, 2018. Disponível em: https://www.revistas.usp.br/organicom/article/view/155286/153062 Acesso em: 20 nov. 2020. 
NUBANK. Dia 29 é o Dia Internacional do Gamer. São Paulo, 26 ago. 2020a. Instagram: Nubank @nubank. Disponível em:

https://www.instagram.com/p/CEWvFawASwk/> Acesso em: 20 nov. 2020.

NUBANK. Pix para lá, Pix para cá, e a gente aqui respondendo todas as suas dúvidas. Se quiser saber mais, é só entrar no link da bio. São Paulo, 26 ago. 2020b. Instagram: Nubank @nubank. Disponível em:

https://www.instagram.com/p/CEZOSPegKLt/. Acesso em: 20 nov. 2020.

NUBANK. O visual da aba de cartão de crédito mudou! Em outras palavras [...]. São Paulo, 28 ago. 2020c. Instagram: Nubank @nubank. Disponível em: https://www.instagram.com/p/CEb-xl0ghR5/. Acesso em: 20 nov. 2020.

NUBANK. A vida financeira é como uma montanha russa, cheia de emoções: a cada boleto a conta desce e a cada TED [...]. São Paulo, 31 ago. 2020d. Instagram: Nubank @nubank. Disponível em: https://www.instagram.com/p/CEjmVQggph8/. Acesso em: 20 nov. 2020.

RECUERO, Raquel. Redes sociais na internet. Porto Alegre: Sulina, 2014.

SANTAELLA, Lúcia. A ecologia pluralista da comunicação: conectividade, mobilidade, ubiquidade. São Paulo: Paulus, 2010.

SANTAHELENA, Raul. Truthtelling: por marcas mais humanas, autênticas e verdadeiras. Curitiba: Voo, 2018.

SCOLARI, Carlos A. Ecología de los Medios. Mapa de un nicho teórico. Quaderns del CAC, v. 13, n. 1, p.17-26, Jun. 2010.

SOUZA, Vanessa Delfino. Marketing de relacionamento para fidelizar clientes: Uma análise da startup Nubank. 2018. 34 f. Artigo de conclusão de Curso (Publicidade e Propaganda) Universidade do Sul de Santa Catarina, Tubarão, Santa Catarina, 2018. Disponível em: https://www.riuni.unisul.br/handle/12345/6860. 